\title{
OBITUARY
}

\section{Ashok Hans: Breaking barriers}

Spinal Cord (2009) 47, 581; doi:10.1038/sc.2009.7

Ashok was born in India in 1950. He was a good speaker, and an extraordinary athlete, he captained the cricket team in school, college and the University. In 1974, he sustained a spinal cord injury (SCI). After rehabilitation under Dr Mary Verghese in CMC Hospital Vellore, he found no opportunity for employment.

In 1984, he met Professor AB Rossier who invited him to join the International Medical Society of Paraplegia (IMSOP). The following year, he setup Shanta Memorial Rehabilitation Centre in Bhubaneswar with the aim of developing SCI services in the region. IMSOP continuously supported his commitments to spinal cord injury (SCI). Sir George Bedbrook, Helmut Madersbacher, Douglas Brown, TS Kanaka, BP Gardner, SY Lee, TK Shanmugasundaram and Paul Dollfus devotedly assisted his campaign for better SCI services. He organized a regional conference of IMSOP in 1991 in Bhubaneswar to which many of them came.
Ashok's greatest contribution was what he termed 'comprehensive community-based rehabilitation of persons with SCI' in rural poor communities. This model started with institutional care and ended with community integration. It included career training, modified housing, livelihood training and sexual and marriage counselling. This model has led to significant reduction in morbidity and reduction of mortality from $75 \%$ to $1 \%$. His latest work has been on SCI in disasters. He used his vision to promote good services mostly for the poor with SCI. He received many national and international awards.

His family, friends, colleagues and the people with SCI who have benefited from his vision and energy mourn his untimely death on 18 July 2008. The ongoing SCI services in Orissa are his chief memorial.

Asha Hans, his sister, and his colleague the hand surgeon Mr Santosh Rath, provided the information in this obituary.

Professor Douglas J Brown Victorian Spinal Cord Service, Austin Health, Heidelberg, Victoria, Australia E-mail: DouglasJ.Brown@austin.org.au 